\title{
IN VITRO ASSESSMENT OF PHYSIOLOGICAL PROPERTIES OF ENTEROCOCCUS STRAINS OF HUMAN ORIGIN FOR POSSIBLE PROBIOTIC USE
}

\author{
ASHLESHA BHAGWAT ${ }^{1}$, NANDANWAR Y $\mathrm{S}^{2}$, RAHUL WARKE ${ }^{3}$ UDAY S ANNAPURE ${ }^{1 *}$ \\ ${ }^{1}$ Department of Food Engineering and Technology, Institute of Chemical Technology, Mumbai, Maharashtra, India. ${ }^{2}$ Department of \\ Obstetrics and Gynecology, Lokmanya Tilak Municipal Corporation General Hospital, Sion, Mumbai, Maharashtra, India. \\ ${ }^{3}$ HiMedia Laboratories Pvt. Ltd., Mumbai, Maharashtra, India. Email: udayannapure@gmail.com
}

Received: 03 April 2019, Revised and Accepted: 29 April 2019

ABSTRACT

Objective: The human vagina and gut are known to harbor a wide range of bacteria. Some useful bacteria maintain the vaginal pH around 3-4.5. This acidity of the vagina helps to inhibit pathogenic organisms that cause urogenital infections. The present study involved screening of previously identified Enterococcus strains of human origin for their probiotic physiological properties.

Materials and Methods: The strains were screened for their biofilm, antibiofilm, antagonistic, antibiotic resistance, adherence, aggregating, and hydrogen peroxide production abilities.

Results: Enterococcus canintestini S26B, Entamoeba dispar S27A, E. dispar S26A, E. dispar S20B, E. canintestini AB2, Enterococcus villorum SB2, and Enterococcus rivorum $\mathrm{S} 22 \mathrm{C}$ displayed in vitro probiotic properties.

Conclusions: These strains can be used as probiotic candidates and may prove their potential in human or animal feed only after further clinical studies.

Keywords: Enterococcus, Probiotic, Biofilm, Adherence, Antimicrobial, Aggregation, Hydrogen peroxide.

(c) 2019 The Authors. Published by Innovare Academic Sciences PvtLtd. This is an open access article under the CCBY license (http://creativecommons org/licenses/by/4. 0/) DOI: http://dx.doi.org/10.22159/ajpcr.2019.v12i6.33294

\section{INTRODUCTION}

The Food and Agriculture Organization (FAO) defines probiotics as "live organisms which, when used in adequate amounts, confer a health benefit on the host" [1]. Probiotic organisms are incorporated in food supplements or used as therapeutic agents to developing a balanced gut microbiota thus boosting the immune system of the host. Bacteria such as bifidobacteria, Escherichia coli, pediococci, yeasts, enterococci, and lactobacilli are widely used as probiotics. The genus Enterococcus belonged to Group-D streptococci and was separated as a new genus in the 1980s. Enterococcus faecium is a reported probiotic strains [2]. Recent studies have proved the beneficial properties of Enterococcus durans, Enterococcus mundtii, Enterococcus faecalis, Enterococcus lactis, etc. [3-5]. In general, these strains are combined with other well-known strains in probiotic formulas. Probiotic strain E. faecium SF68 has proved its efficacy in treating antibiotic-associated diarrhea [6]. Although Lactobacillus and Enterococcus species are recently found in nosocomial infection; it has given rise to its safety concern on its use $[7,8]$. The possession of virulence genes does not necessarily prove the strain to be pathogenic as proposed by the European Food Safety Authority (EFSA). The expression of virulence genes is extremely dependent on environmental conditions [9]. However, some studies have reported that intrinsic resistance to antibiotics could be seen as an advantage for patients with diarrheal infection or patients trying to avoid antibiotic-caused diarrhea. In several studies, vaginal enterococci and lactobacilli have been detected or isolated from meconium, amniotic fluid, placenta, membranes, etc., that have caused no infections in the mother-infant pair [10-12].

The human vagina is a diverse source of lactic acid bacteria. They inhibit the pathogenic organisms by producing various organic acids, hydrogen peroxide, and antimicrobial substances called bacteriocins. These bacteria are present in large numbers on the vaginal lateral walls and contribute to the acidity of the vagina. They compete with the other pathogenic organisms and maintain the healthy gut ecosystem. The vaginal microbiota is responsible for the natural oral inoculation of the newborn [13].

To use a bacterial strain as a probiotic candidate, it must be deposited in recognized strain libraries and should have passed the proposed guidelines. FAO has recommended that a probiotic strain used for human/animal consumption must be of human or animal origin, acid and bile tolerant, avirulent, show an antagonistic effect on pathogens, adhere to gastrointestinal tract (GIT), and possess antioxidant activity. These probiotic attributes of strains help in effective colonization in the GIT and balance gut microbiota of the host $[1,14]$.

Probiotic studies have been extensively carried out for lactobacilli, while very few probiotic characteristics are reported of Enterococcus strains [15]. The present study is aimed at the screening of identified Enterococcus isolates of human origin for their tolerance to pancreatic juices, antagonistic activity, adherence to polystyrene plate, microbial adhesion to solvents (MATS), and hydrogen peroxide forming abilities.

\section{MATERIALS AND METHODS}

\section{Bacterial strains and growth conditions}

Healthy human vagina and GIT are important sources of gut-stabilizing beneficial bacteria. Maternal microbiota is the foundation of gut development of the neonate. Hence, the present study included 13 Enterococcus strains isolated from the human vagina and fresh meconium of the neonates. An informed consent was obtained from the healthy individuals and the study was approved by the Ethics Committee of Lokmanya Tilak Municipal Corporation General Hospital, Mumbai, India. The isolates were identified biochemically followed by 16S rRNA sequencing and deposited to the NCBI GenBank Database under accession numbers KX 830968 - KX 830982. All the isolates were grown in Man-Rogosa-Sharpe (MRS) broth (HiMedia, Mumbai) 
at $37^{\circ} \mathrm{C}$ aerobically. These strains were then maintained and preserved in MRS broth supplemented with $40 \%$ glycerol (HiMedia, Mumbai) at $-20^{\circ} \mathrm{C}$ and sub-cultured periodically when needed. The strains were sub-cultured in MRS broth before use for each assay. The well-known commercially used probiotic Lactobacillus casei Shirota strain (L. casei YIT 9029) was used as a reference strain for comparison in all the assays.

\section{Tolerance to pancreatic enzymes}

The isolates were checked for their tolerance to pancreatic enzymes. Enzymes such as pepsin $(0.5 \mathrm{mg} / \mathrm{ml})$ from porcine pancreas, trypsin $(0.5 \mathrm{mg} / \mathrm{ml})$ (HiMedia, Mumbai), and pancreatic $\alpha$-amylase $(220 \mathrm{IU} \mathrm{mg} / \mathrm{ml})$ of bovine origin were procured from Advanced Enzymes, Mumbai. The enzymes with desired concentration were suspended in phosphatebuffered saline (PBS, pH 7.4) and were incubated with the strains for $1 \mathrm{~h}$ at $30^{\circ} \mathrm{C}$ followed by incubation at $37^{\circ} \mathrm{C}$ for an hour. The strain viability was checked by spread plating on MRS agar before and after incubation. MRS broth without enzymes was used as a control in the experiment [16].

\section{Antimicrobial activity}

Fresh overnight cultures of lactobacilli grown in MRS broth were centrifuged at $8000 \mathrm{~g}$ for $10 \mathrm{~min}$. The cells were digested with simulated gastric juice to imitate passage in vivo stomach and intestinal conditions. Enteric pathogens such as E. coli

ATCC 8739, Pseudomonas aeruginosa ATCC 27853, Klebsiella pneumoniae ATCC 13883, and Salmonella typhi ATCC 6539 were included in the study. Actively growing $18 \mathrm{~h}$ old pathogenic strains were swabbed (Optical density [OD] 0.5 at $620 \mathrm{~nm}$ ) on MRS agar plates. Test cultures were spot inoculated in the center of the plate. Plates were incubated for $24 \mathrm{~h}$ and zone of inhibition was measured produced by the test culture [3].

\section{Antibiotic susceptibility}

E-test strips of varied concentrations of the antibiotic ampicillin (0.016-256), gentamycin (0.01-256), streptomycin (0.001-256), tetracycline (0.01-256), chloramphenicol (0.001-256), and vancomycin (0.001-256) in $\mu \mathrm{g} / \mathrm{ml}$ units were used and were purchased from HiMedia, Mumbai. Actively growing $18 \mathrm{~h}$ old culture of OD $0.4(560 \mathrm{~nm})$ was swabbed on Mueller-Hinton agar plates. The E-test strips were placed on the plate and incubated for $18 \mathrm{~h}$. The minimum inhibitory concentration (MIC) was interpreted by measuring the zone of inhibition at the given antibiotic concentration, and the strains were considered to be sensitive or resistant by comparing with the breakpoints recommended by EFSA for Enterococcus genus. Strains showing MIC above the breakpoint were termed as resistant strain $[17,18]$.

\section{Screening of virulence factors}

The enterococcal strains were screened for the presence of virulence factors such as cyl $A$; cytolysin expression, van $A$ and van $B$; vancomycin resistance, gel E; esp; efaAfs; and efaAfm; cell wall adhesin genes. The DNA from an overnight culture was obtained to perform PCR analysis as described by Eaton and Gasson [19].

\section{Biofilm formation}

Briefly, $200 \mu \mathrm{l}$ of each test culture $\left(3 \times 10^{7} \mathrm{cfu} / \mathrm{ml}\right)$ was inoculated in $5 \mathrm{ml}$ of MRS broth. Aliquot of $200 \mu \mathrm{l}$ of the above mixture was placed in 96well microtiter plate (Tarsons, Mumbai) and incubated at $37^{\circ} \mathrm{C}$ for $24 \mathrm{~h}$ and $72 \mathrm{~h}$ in static condition. The wells were washed with $200 \mu \mathrm{l}$ sterile PBS ( $\mathrm{pH}$ 7). The attached bacteria were stained with $200 \mu \mathrm{l}$ of $0.1 \%$ of crystal violet for $30 \mathrm{~min}$. The excess stain was washed with $200 \mu \mathrm{l}$ of distilled water per well and the dye bound was extracted with $200 \mu \mathrm{l}$ of $30 \%$ glacial acetic acid. Around $135 \mu \mathrm{l}$ of above aliquot was extracted in a separate plate and optical absorbance (OD) was determined on an Hitachi Spectrophotometer, pathlength $(\sim 0.4$ for volume $135 \mu \mathrm{l})$. The assay was repeated in triplicates [20].

\section{Antibiofilm activity}

The antibiofilm activity was assessed to study the inhibition of biofilmforming pathogenic organisms by the potential probiotics. This activity was determined using the 96-well polystyrene plate method. The pathogenic strains recommended by ATCC for food and water testing such as P. aeruginosa ATCC 27853, E. coli ATCC 8739, K. pneumoniae ATCC 13883, and S. typhi ATCC 6539 were used in the study. $10 \mu \mathrm{l}$ $\left(10^{6} \mathrm{cfu} / \mathrm{ml}\right)$ of each pathogen strain was inoculated into the well. The cell-free supernatant of enterococci strains was obtained by centrifuging the cells at $8000 \mathrm{rpm}$ at $4^{\circ} \mathrm{C}$ for $10 \mathrm{~min}$. The resulting supernatant was filtered through $0.22 \mu \mathrm{m}$ Merck-Millipore filter and neutralized to adjust $\mathrm{pH}$ 7. The cell-free supernatant of enterococci strains with concentration ranging from $0,10,20,30$, and $40 \mu \mathrm{l}$ was added to each well-containing indicator strain. The total volume of $250 \mu \mathrm{l}$ was adjusted by adding tryptone soy broth (HiMedia, Mumbai). MRS broth with indicator but without any supernatant was used as control and incubated at $37^{\circ} \mathrm{C}$ for $24 \mathrm{~h}$. The culture was poured off from wells and washed with $300 \mu \mathrm{l}$ PBS. The bacteria were fixed with $250 \mu \mathrm{l}$ of methanol for $15 \mathrm{~min}$. The methanol was removed and the plates were air dried at room temperature. The bacteria were then stained with $250 \mu \mathrm{l}$ of $1 \%$ crystal violet for $5 \mathrm{~min}$. The excess stain was washed with water. The plates were air dried and absorbance was noted at $620 \mathrm{~nm}$ [21].

\section{Adherence assay}

The cell surface hydrophobicity was assessed by screening the isolates by streaking on CR-MRS agar plates containing $0.01 \%$ Congo red and incubated at $37^{\circ} \mathrm{C}$ for $48 \mathrm{~h}$. The colonies which took up the red dye were considered to be adherent [22].

The same was assessed quantitatively by adhesion of crystal violet stained bacteria to 96 well microtiter plate obtained from Tarsons, Mumbai. Briefly, $100 \mu \mathrm{l}$ of $5 \times 10^{8} \mathrm{cfu} / \mathrm{ml}$, (OD $0.5650 \mathrm{~nm}$, test culture was added to each well of a microtiter plate incubate for $2 \mathrm{~h}$ at $37^{\circ} \mathrm{C}$. The bacteria were washed off with $200 \mu$ PBS. The plates were dried for $1 \mathrm{~h}$ at room temperature. $0.2 \%$ of crystal violet stain was then added and kept for $15 \mathrm{~min}$. The stain was removed and the wells were washed thrice with PBS. After drying the plates for $15 \mathrm{~min}$ at room temperature, absorbance was noted at $595 \mathrm{~nm}$ on Hitachi Spectrophotometer. The experiment was conducted in triplicates [23].

\section{Microbial adhesion to solvents (MATS)}

The probiotic isolates were screened for their hydrophobic nature. Briefly, $10 \mathrm{ml}$ of $18 \mathrm{~h}$ old culture was re-suspended in PBS and set to absorbance $0.4(590 \mathrm{~nm})$. From this culture suspension, $3 \mathrm{ml}$ was removed separately in a tube and $1 \mathrm{ml}$ of solvents such as chloroform, ethyl acetate, and hexadecane was added. The mixture was vortexed for $3 \mathrm{~min}$ and allowed to stand for $30 \mathrm{~min}$ to allow phase separation. The aqueous layer approximately $10 \mu \mathrm{l}$ was removed carefully without disturbing the system and its OD $590 \mathrm{~nm}$ was noted. This experiment was performed in triplicates and percentage affinity toward solvents was calculated as follows: Pecent affinity $=100 \times\left\{1-\left(A_{1} / A_{0}\right)\right\}$, where $A_{0}$; initial absorbance, $\mathrm{A}_{1}$; final absorbance at $590 \mathrm{~nm}$ [24].

\section{Quantification of hydrogen peroxide}

The hydrogen peroxide production was evaluated by the titrimetric method. Briefly, $25 \mathrm{ml}$ of $48 \mathrm{~h}$ old incubated broth test culture and $25 \mathrm{ml}$ of dilute $\mathrm{H}_{2} \mathrm{SO}_{4}(0.1 \mathrm{M})$ to $100 \mathrm{ml}$ flask. Then, the mixture was titrated against $0.1 \mathrm{M} \mathrm{KMNO}_{4}$ until the solution changes to pink color. Each 0.1 $\mathrm{M} \mathrm{KMNO}_{4}$ corresponds to $1.701 \mathrm{mg}$ of $\mathrm{H}_{2} \mathrm{O}_{2}$. The percent $\mathrm{H}_{2} \mathrm{O}_{2}$ produced was calculated according to the AOAC standards using the formula

$$
\text { Percent } \mathrm{H}_{2} \mathrm{O}_{2}=\mathrm{EP}_{1} \times \mathrm{CO}_{1} \times \mathrm{CO}_{2} / \mathrm{CO}_{0} ;
$$

Where $\mathrm{EP}_{1}=\mathrm{ml}$ of $\mathrm{KMNO}_{4}$ required for endpoint; $\mathrm{CO}_{0}=$ sample size; $\mathrm{CO}_{1}=1.701 ; \mathrm{CO}_{2}=0.1[25]$.

\section{Autoaggregation and coaggregation assay}

The test cultures were checked for their autoaggregation and coaggregation abilities with pathogenic bacteria such as E. coli ATCC 8739, P. aeruginosa ATCC 27853, S. typhi ATCC 6539, and K. pneumoniae ATCC 13883. L. casei Shirota was used as a positive control. $24 \mathrm{~h}$ old culture was centrifuged at $8000 \mathrm{rpm}$ and washed twice with PBS 
resuspend the cultures in $1 \mathrm{ml}$ of PBS. Pipette out $230 \mu \mathrm{l}$ of culture from the upper layer in a microtiter plate and check for absorbance at $420 \mathrm{~nm}$ on Hitachi Spectrophotometer. The absorbance readings were taken at an hourly interval up to $4 \mathrm{~h}$ [26].

\section{Statistical analysis}

All the experiments were performed in triplicates. The statistical significance was derived using Analysis of variance in Statistical Package for the Social Sciences software for Windows version (16.0). Post hoc tests like Duncan were approached to show the significance at $\mathrm{p}<0.05$.

\section{RESULTS}

The isolates were screened for their tolerance to pancreatic enzymes such as pepsin, trypsin, and alpha-amylase. Table 1 shows the viability of the strains after incubation. All the strains were able to maintain at least $10^{5}-10^{7} \mathrm{cfu} / \mathrm{ml}$ in harsh or bactericidal enzymes such as pepsin, trypsin, and pancreatin

\section{Antimicrobial activity}

The antibacterial activity of strains showed a broad-spectrum activity against a set of indicator strains. Table 2 shows the inhibitory activity by spot inoculation test. All of the tested strains show a broad spectrum of activity against indicator strains such as E. coli ATCC 8739, K. pneumoniae ATCC 13883, P. aeruginosa ATCC 27853, and S. typhi ATCC 6539.

\section{Antibiotic susceptibility}

The antibiotic susceptibility of the isolates was assessed by the E-test strip method. Table 3 elucidates the sensitivity of the strains to the antibiotics included in the study. Almost all of the isolates were antibiotic sensitive and were within the cutoff values recommended by EFSA. Only two isolates were equal to MIC cutoff value $(128 \mu \mathrm{g} / \mathrm{ml})$ for streptomycin. This value is within the normal value or equal to mean and hence does not need any further investigation regarding its concern in food safety.

\section{Biofilm formation}

All the strains displayed biofilm formation on polystyrene plates following $24 \mathrm{~h}$ (Fig.2 ) and 72h (Fig.1) incubation. Enterococcus canintestini S26B, Enterococcus dispar S27A, E. dispar S26A, E. dispar S20B, E. canintestini AB2, Enterococcus villorum SB2, and Enterococcus rivorum $\mathrm{S} 22 \mathrm{C}$ strains displayed excellent adherence abilities $(\mathrm{OD} \geq 1.0)$. E. canintestini S18A, E. dispar S16B, E. canintestini AB1, E. canintestini SB3, E. phoeniculicola S20A, and E. rivorum S14B displayed fairly adherent properties $(0.5 \leq 0 \mathrm{D} \leq 1)$.

\section{Antibiofilm activity}

The antibiofilm activity with different volumes of cell-free supernatant of the enterococcal strains was assessed after $24 \mathrm{~h}$ incubation with indicator strains. Table 4 shows the antibiofilm activity of the

Table 1: Effect of pancreatic enzymes on cell viability tolerance to pancreatic enzymes

\begin{tabular}{|c|c|c|c|c|}
\hline \multirow[t]{2}{*}{ Strains } & \multicolumn{4}{|c|}{ Viable count $\log \mathrm{cfu} / \mathrm{ml}$ after $2 \mathrm{~h}$} \\
\hline & Control & Pepsin & Trypsin & $\alpha$-Amylase \\
\hline E. rivorum S14B & $7.37 \pm 0.51^{\mathrm{a}}$ & $6.6 \pm 0.36^{\mathrm{ab}}$ & $7.46 \pm 0.28^{\mathrm{cd}}$ & $5.35 \pm 0.62^{\mathrm{a}}$ \\
\hline E. villorum SB2 & $7.62 \pm 0.42^{\mathrm{b}}$ & $7.02 \pm 0.52^{\mathrm{abcd}}$ & $7.49 \pm 0.46^{\mathrm{cd}}$ & $5.57 \pm 0.19^{\mathrm{a}}$ \\
\hline E. canintestini SB3 & $7.8 \pm 0.34^{\mathrm{ab}}$ & $6.9 \pm 0.42^{\mathrm{abc}}$ & $7.39 \pm 0.73^{\mathrm{cd}}$ & $5.77 \pm 0.21^{\mathrm{a}}$ \\
\hline E. canintestini $\mathrm{AB} 1$ & $8.32 \pm 0.82^{\mathrm{abc}}$ & $7.2 \pm 0.33^{\mathrm{abcd}}$ & $7.48 \pm 0.64^{\mathrm{cd}}$ & $5.47 \pm 0.34^{\mathrm{a}}$ \\
\hline E. canintestini S18A & $8.1 \pm 0.64^{\mathrm{abc}}$ & $7.41 \pm 0.28^{\mathrm{bcd}}$ & $7.77 \pm 0.25^{\mathrm{d}}$ & $6.62 \pm 0.57^{\mathrm{b}}$ \\
\hline E. dispar $\mathrm{S} 20 \mathrm{~B}$ & $7.68 \pm 0.27^{\mathrm{ab}}$ & $7.49 \pm 0.41^{\mathrm{cd}}$ & $7.507 \pm 0.34^{\mathrm{cd}}$ & $5.50 \pm 0.49^{\mathrm{a}}$ \\
\hline E. rivorum $\mathrm{S} 22 \mathrm{C}$ & $7.49 \pm 0.38^{\mathrm{a}}$ & $6.39 \pm 0.66^{\mathrm{a}}$ & $6.45 \pm 0.29^{b}$ & $7.49 \pm 0.38^{\mathrm{c}}$ \\
\hline E. dispar S27A & $7.52 \pm 0.34^{\mathrm{ac}}$ & $6.53 \pm 0.53^{\mathrm{a}}$ & $5.43 \pm 0.13^{\mathrm{a}}$ & $6.83 \pm 0.26^{\mathrm{bc}}$ \\
\hline E. canintestini $\mathrm{AB} 2$ & $8.23 \pm 0.19^{\mathrm{abc}}$ & $6.48 \pm 0.78^{a}$ & $7.8 \pm 0.42^{\mathrm{d}}$ & $6.21 \pm 0.61^{\mathrm{ab}}$ \\
\hline E. dispar $\mathrm{S} 26 \mathrm{~A}$ & $8.65 \pm 0.56^{\mathrm{b}}$ & $7.89 \pm 0.36^{d}$ & $7.48 \pm 0.7^{\mathrm{cd}}$ & $5.58 \pm 0.39^{\mathrm{a}}$ \\
\hline E. dispar S16B & $7.57 \pm 0.72^{\mathrm{ab}}$ & $6.7 \pm 0.21^{\mathrm{ab}}$ & $6.46 \pm 0.61^{b}$ & $6.62 \pm 0.27^{\mathrm{b}}$ \\
\hline E. canintestini S26B & $9.11 \pm 0.66^{\mathrm{ac}}$ & $7.55 \pm 0.19^{c}$ & $7.94 \pm 0.31^{\mathrm{d}}$ & $5.71 \pm 0.43^{\mathrm{a}}$ \\
\hline L. casei Shirota & $7.72 \pm 0.41^{\mathrm{ab}}$ & $6.69 \pm 0.43^{\mathrm{abc}}$ & $6.68 \pm 0.28^{\mathrm{bc}}$ & $6.688 \pm 0.67^{b}$ \\
\hline
\end{tabular}

Values reported are mean \pm SD of triplicate experiments. Values within each row and column with the different letter assigned are significantly different $P<0.05$. E. rivorum: Enterococcus rivorum, E. phoeniculicola: Enterococcus phoeniculicola, Enterococcus villorum, E. canintestini: Enterococcus canintestini,

E. dispar: Entamoeba dispar, L. casei Shirota: Lactobacillus casei Shirota

Table 2: Antimicrobial activity profile of the Enterococcus strains by spot inoculation test

\begin{tabular}{|c|c|c|c|c|}
\hline \multirow[t]{2}{*}{ Strains } & \multicolumn{4}{|c|}{ Inhibition zone against indicator organism $(\mathrm{mm})^{\mathrm{a}}$} \\
\hline & E. coli & K. pneumoniae & P. aeruginosa & S. typhi \\
\hline E. villorum SB2 & $9.7 \pm 0.3$ & $9.1 \pm 0.12$ & $7.2 \pm 0.2$ & $9.2 \pm 0.15$ \\
\hline E. phoeniculicola S20A & $9.4 \pm 0.11$ & $8.2 \pm 0.15$ & $9.1 \pm 0.26$ & $8.4 \pm 0.3$ \\
\hline E. rivorum $\mathrm{S} 14 \mathrm{~B}$ & $8.5 \pm 0.25$ & $10.8 \pm 0.21$ & $18.8 \pm 0.21$ & $7.3 \pm 0.3$ \\
\hline E. canintestini $\mathrm{AB} 2$ & $18.1 \pm 0.31$ & $6.9 \pm 0.12$ & $14.2 \pm 0.35$ & $7.2 \pm 0.25$ \\
\hline E. rivorum $\mathrm{S} 22 \mathrm{C}$ & $11.5 \pm 0.2$ & $9.2 \pm 0.2$ & $12.2 \pm 0.2$ & $7.3 \pm 0.31$ \\
\hline E. canintestini S18A & $12.3 \pm 0.42$ & $7.9 \pm 0.21$ & ND & $9.3 \pm 0.25$ \\
\hline E. canintestini SB3 & $9.4 \pm 0.36$ & $8.0 \pm 0.07$ & $9.3 \pm 0.25$ & $8.6 \pm 0.15$ \\
\hline E. canintestini $\mathrm{AB} 1$ & $8.4 \pm 0.50$ & $8.5 \pm 0.17$ & $12.4 \pm 0.1$ & $7.3 \pm 0.3$ \\
\hline E. dispar S16B & $9 \pm 0.46$ & $8.3 \pm 0.3$ & $9.3 \pm 0.46$ & $12.3 \pm 0.45$ \\
\hline E. dispar S26A & $13.4 \pm 0.40$ & $13.3 \pm 0.2$ & $8.3 \pm 0.1$ & $11.4 \pm 0.31$ \\
\hline E. dispar $\mathrm{S} 27 \mathrm{~A}$ & $9.5 \pm 0.25$ & ND & ND & $12.3 \pm 0.26$ \\
\hline E. canintestini S26B & $10.2 \pm 0.38$ & $9.3 \pm 0.2$ & ND & $11.6 \pm 0.15$ \\
\hline E. dispar $\mathrm{S} 20 \mathrm{~B}$ & $12.5 \pm 0.25$ & $10.2 \pm 0.31$ & ND & $12.1 \pm 0.21$ \\
\hline L. casei Shirota & $12.56 \pm 0.34$ & $11.67 \pm 0.37$ & $12.58 \pm 0.21$ & $13.84 \pm 0.24$ \\
\hline
\end{tabular}

aalues represent the mean \pm s.e.m. of three independent experiments. ${ }^{\mathrm{b}}$ Not detected; inhibition zones with values $\leq 5 \mathrm{~mm}$ were assumed as the absence of antimicrobial activity. E. villorum: Enterococcus villorum, E. phoeniculicola: Enterococcus phoeniculicola, E. rivorum: Enterococcus rivorum, E. canintestini: Enterococcus canintestini,

E. dispar: Entamoeba dispar, L. casei Shirota: Lactobacillus casei Shirota 
Table 3: Antibiotic susceptibility of Enterococci strains

\begin{tabular}{|c|c|c|c|c|c|c|c|c|c|c|c|c|c|}
\hline \multirow[t]{2}{*}{ Antibiotics } & \multicolumn{12}{|c|}{ Number of strains with the indicated MIC (mg/L) } & \multirow{2}{*}{$\begin{array}{l}\text { EFSA } \\
\text { Breakpoints (mg/L) }\end{array}$} \\
\hline & 0.12 & 0.25 & 0.5 & 1 & 2 & 4 & 8 & 16 & 32 & 64 & 128 & 256 & \\
\hline Ampicillin & 1 & - & 7 & 3 & 2 & & & & & & & & 2 \\
\hline Streptomycin & & & & & & 1 & & 1 & 5 & 4 & 2 & & 128 \\
\hline Tetracycline & 9 & 3 & 1 & & & & & & & & & & 4 \\
\hline Chloramphenicol & & & & 7 & 4 & 4 & & & & & & & 4 \\
\hline Vancomycin & 10 & 1 & 2 & & & & & & & & & & 4 \\
\hline
\end{tabular}

EFSA: European Food Safety Authority, MIC: Minimum inhibitory concentration

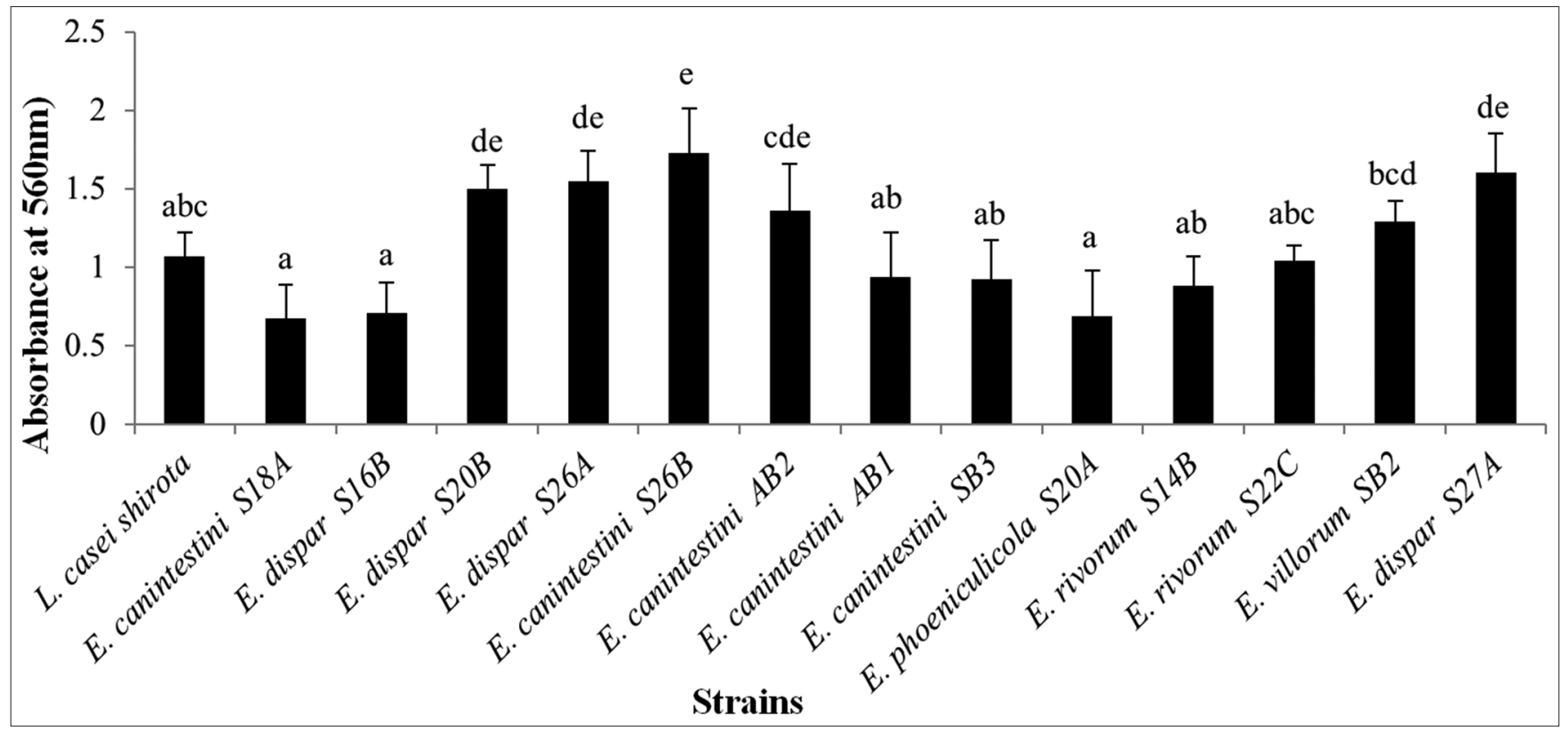

Fig. 1: Biofilm formation of Enterococcus strains on polystyrene plates after $\mathbf{7 2} \mathbf{h}$. The biofilm formation was determined by turbidity of crystal violet stained bacteria adhering to the polystyrene plate

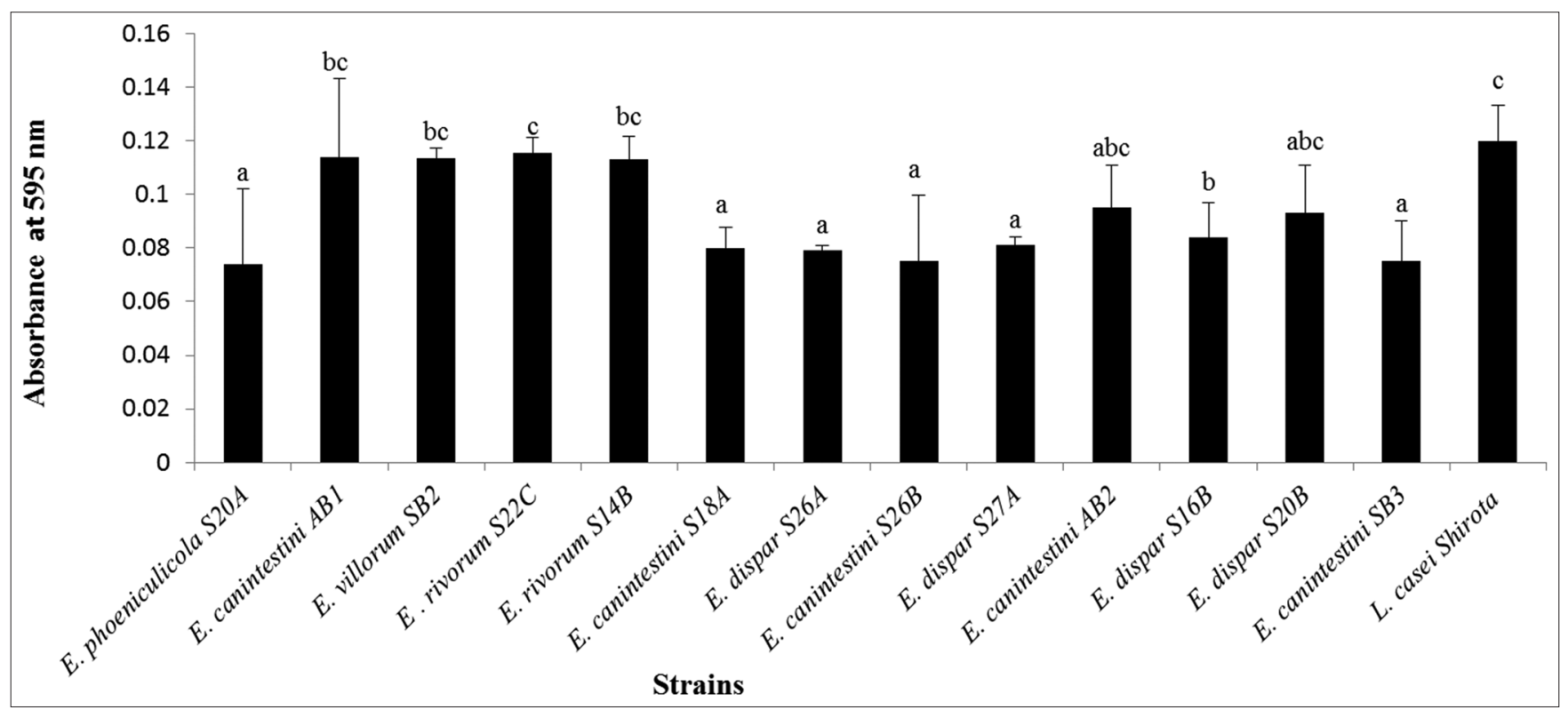

Fig. 2: Adherence of Enterococcus strains to polystyrene plate after $24 \mathrm{~h}$

Enterococcus strains. All the strains inhibited the biofilm formation by reducing growth. Higher inhibition was observed against pathogens E. coli ATCC 8739, P. aeruginosa ATCC 27853, and S. typhi ATCC
6539. The activity was seen to increase with the concentration of the supernatant as compared to control without supernatant. The control indicator strains showed medium to high biofilm formation. 
Table 4: Antibiofilm activity

\begin{tabular}{|c|c|c|c|c|c|}
\hline \multirow[t]{2}{*}{ Strain } & \multirow{2}{*}{$\begin{array}{l}\text { Amount of } \\
\text { supernatant }(\mu l)\end{array}$} & \multicolumn{4}{|c|}{ Antibiofilm activity O.D at $595 \mathrm{~nm}$} \\
\hline & & E. coli & P. aeruginosa & S. typhi & K. pneumoniae \\
\hline Control & 0 & $0.97 \pm 0.054$ & $0.85 \pm 0.021$ & $0.89 \pm 0.076$ & $1.02 \pm 0.112$ \\
\hline \multirow{3}{*}{ E. canintestini SB3 } & 20 & $0.86 \pm 0.065$ & $0.42 \pm 0.02$ & $0.54 \pm 0.02$ & $0.83 \pm 0.03$ \\
\hline & 30 & $0.53 \pm 0.251$ & $0.253 \pm 0.03$ & $0.28 \pm 0.05$ & $0.76 \pm 0.05$ \\
\hline & 40 & $0.27 \pm 0.154$ & $0.124 \pm 0.067$ & $0.212 \pm 0.024$ & $0.418 \pm 0.016$ \\
\hline \multirow[t]{4}{*}{ E. canintestini S18A } & 10 & $0.97 \pm 0.073$ & $0.81 \pm 0.035$ & $0.81 \pm 0.09$ & $0.98 \pm 0.01$ \\
\hline & 20 & $0.88 \pm 0.064$ & $0.78 \pm 0.149$ & $0.7 \pm 0.049$ & $0.92 \pm 0.053$ \\
\hline & 30 & $0.61 \pm 0.118$ & $0.418 \pm 0.087$ & $0.53 \pm 0.061$ & $0.75 \pm 0.32$ \\
\hline & 40 & $0.301 \pm 0.059$ & $0.216 \pm 0.01$ & $0.29 \pm 0.049$ & $0.62 \pm 0.119$ \\
\hline \multirow[t]{4}{*}{ E. canintestini $\mathrm{AB} 1$} & 10 & $0.92 \pm 0.1189$ & $0.79 \pm 0.02$ & $0.83 \pm 0.048$ & $0.95 \pm 0.135$ \\
\hline & 20 & $0.76 \pm 0.02$ & $0.534 \pm 0.36$ & $0.76 \pm 0.047$ & $0.84 \pm 0.062$ \\
\hline & 30 & $0.57 \pm 0.25$ & $0.205 \pm 0.077$ & $0.41 \pm 0.393$ & $0.63 \pm 0.043$ \\
\hline & 40 & $0.135 \pm 0.108$ & $0.196 \pm 0.063$ & $0.22 \pm 0.065$ & $0.47 \pm 0.059$ \\
\hline \multirow[t]{3}{*}{ E. phoeniculicola S20A } & 10 & $0.93 \pm 0.075$ & $0.83 \pm 0.137$ & $0.87 \pm 0.135$ & $0.921 \pm 0.04$ \\
\hline & 20 & $0.83 \pm 0.09$ & $0.756 \pm 0.132$ & $0.78 \pm 0.081$ & $0.81 \pm 0.073$ \\
\hline & 40 & $0.198 \pm 0.0745$ & $0.27 \pm 0.038$ & $0.305 \pm 0.058$ & $0.308 \pm 0.0202$ \\
\hline \multirow[t]{4}{*}{ E. canintestini S26B } & 10 & $0.89 \pm 0.33$ & $0.77 \pm 0.05$ & $0.85 \pm 0.169$ & $0.954 \pm 0.096$ \\
\hline & 20 & $0.82 \pm 0.03$ & $0.64 \pm 0.06$ & $0.67 \pm 0.028$ & $0.82 \pm 0.03$ \\
\hline & 30 & $0.6 \pm 0.068$ & $0.43 \pm 0.021$ & $0.33 \pm 0.048$ & $0.716 \pm 0.03$ \\
\hline & 40 & $0.27 \pm 0.3$ & $0.26 \pm 0.081$ & $0.18 \pm 0.032$ & $0.421 \pm 0.017$ \\
\hline \multirow[t]{4}{*}{ E. dispar $\mathrm{S} 27 \mathrm{~A}$} & 10 & $0.91 \pm 0.112$ & $0.82 \pm 0.166$ & $0.8 \pm 0.067$ & $0.967 \pm 0.053$ \\
\hline & 20 & $0.86 \pm 0.112$ & $0.72 \pm 0.113$ & $0.74 \pm 0.1$ & $0.845 \pm 0.067$ \\
\hline & 30 & $0.51 \pm 0.051$ & $0.53 \pm 0.0825$ & $0.58 \pm 0.115$ & $0.734 \pm 0.098$ \\
\hline & 40 & $0.21 \pm 0.032$ & $0.12 \pm 0.013$ & $0.26 \pm 0.07$ & $0.59 \pm 0.07$ \\
\hline \multirow[t]{4}{*}{ L. casei Shirota } & 10 & $0.88 \pm 0.09$ & $0.75 \pm 0.136$ & $0.81 \pm 0.47$ & $0.91 \pm 0.087$ \\
\hline & 20 & $0.84 \pm 0.052$ & $0.66 \pm 0.074$ & $0.76 \pm 0.037$ & $0.85 \pm 0.016$ \\
\hline & 30 & $0.45 \pm 0.086$ & $0.47 \pm 0.016$ & $0.512 \pm 0.038$ & $0.73 \pm 0.157$ \\
\hline & 40 & $0.18 \pm 0.0118$ & $0.23 \pm 0.074$ & $0.49 \pm 0.063$ & $0.618 \pm 0.044$ \\
\hline \multirow[t]{4}{*}{ E. rivorum $\mathrm{S} 22 \mathrm{C}$} & 10 & $0.92 \pm 0.0144$ & $0.81 \pm 0.05$ & $0.83 \pm 0.23$ & $0.94 \pm 0.088$ \\
\hline & 20 & $0.79 \pm 0.034$ & $0.73 \pm 0.059$ & $0.61 \pm 0.12$ & $0.86 \pm 0.07$ \\
\hline & 30 & $0.419 \pm 0.062$ & $0.52 \pm 0.062$ & $0.53 \pm 0.032$ & $0.71 \pm 0.046$ \\
\hline & 40 & $0.214 \pm 0.092$ & $0.129 \pm 0.114$ & $0.28 \pm 0.094$ & $0.408 \pm 0.06$ \\
\hline E. canintestini $\mathrm{AB} 2$ & 40 & $0.38 \pm 0.093$ & $0.37 \pm 0.16$ & $0.42 \pm 0.062$ & $0.42 \pm 0.072$ \\
\hline \multirow[t]{4}{*}{ E. dispar S20B } & 10 & $0.87 \pm 0.0175$ & $0.81 \pm 0.043$ & $0.823 \pm 0.092$ & $0.96 \pm 0.158$ \\
\hline & 20 & $0.73 \pm 0.034$ & $0.62 \pm 0.18$ & $0.63 \pm 0.03$ & $0.612 \pm 0.071$ \\
\hline & 30 & $0.48 \pm 0.029$ & $0.45 \pm 0.23$ & $0.409 \pm 0.101$ & $0.53 \pm 0.143$ \\
\hline & 40 & $0.27 \pm 0.073$ & $0.29 \pm 0.044$ & $0.367 \pm 0.002$ & $0.415 \pm 0.104$ \\
\hline \multirow[t]{4}{*}{ E. dispar S16B } & 10 & $0.9 \pm 0.019$ & $0.79 \pm 0.015$ & $0.82 \pm 0.004$ & $0.97 \pm 0.097$ \\
\hline & 20 & $0.81 \pm 0.13$ & $0.51 \pm 0.073$ & $0.79 \pm 0.064$ & $0.83 \pm 0.104$ \\
\hline & 30 & $0.53 \pm 0.072$ & $0.34 \pm 0.014$ & $0.514 \pm 0.056$ & $0.619 \pm 0.025$ \\
\hline & 40 & $0.271 \pm 0.018$ & $0.18 \pm 0.214$ & $0.31 \pm 0.19$ & $0.27 \pm 0.22$ \\
\hline \multirow[t]{4}{*}{ E. dispar $\mathrm{S} 26 \mathrm{~A}$} & 10 & $0.88 \pm 0.094$ & $0.8 \pm 0.17$ & $0.85 \pm 0.068$ & $0.93 \pm 0.08$ \\
\hline & 20 & $0.76 \pm 0.083$ & $0.61 \pm 0.082$ & $0.74 \pm 0.036$ & $0.82 \pm 0.034$ \\
\hline & 30 & $0.52 \pm 0.047$ & $0.406 \pm 0.049$ & $0.68 \pm 0.01$ & $0.57 \pm 0.066$ \\
\hline & 40 & $0.16 \pm 0.16$ & $0.208 \pm 0.34$ & $0.56 \pm 0.041$ & $0.419 \pm 0.074$ \\
\hline \multirow{4}{*}{ E. villorum $\mathrm{SB} 2$} & 10 & $0.87 \pm 0.27$ & $0.82 \pm 0.06$ & $0.87 \pm 0.07$ & $0.97 \pm 0.065$ \\
\hline & 20 & $0.62 \pm 0.09$ & $0.79 \pm 0.015$ & $0.72 \pm 0.064$ & $0.815 \pm 0.076$ \\
\hline & 30 & $0.48 \pm 0.02$ & $0.51 \pm 0.046$ & $0.61 \pm 0.074$ & $0.638 \pm 0.074$ \\
\hline & 40 & $0.19 \pm 0.24$ & $0.23 \pm 0.07$ & $0.43 \pm 0.035$ & $0.49 \pm 0.02$ \\
\hline \multirow[t]{4}{*}{ E. rivorum $14 \mathrm{~B}$} & 10 & $0.85 \pm 0.19$ & $0.86 \pm 0.043$ & $0.86 \pm 0.067$ & $0.83 \pm 0.076$ \\
\hline & 20 & $0.63 \pm 0.07$ & $0.78 \pm 0.073$ & $0.64 \pm 0.075$ & $0.61 \pm 0.034$ \\
\hline & 30 & $0.57 \pm 0.084$ & $0.57 \pm 0.16$ & $0.43 \pm 0.19$ & $0.47 \pm 0.072$ \\
\hline & 40 & $0.31 \pm 0.012$ & $0.2 \pm 0.098$ & $0.15 \pm 0.23$ & $0.218 \pm 0.052$ \\
\hline
\end{tabular}

Values reported are mean $\pm \mathrm{SD}$ of three independent experiments. E. canintestini: Enterococcus canintestini, E. phoeniculicola: Enterococcus phoeniculicola, E. dispar: Entamoeba dispar, L. casei Shirota: Lactobacillus casei Shirota, E. rivorum: Enterococcus rivorum, E. villorum: Enterococcus villorum

\section{Screening of virulence factors}

Table 5 shows the screening of virulent genes among the strains.

E. phoeniculicola S20A, E. canintestini S18A and E. dispar S 27A were positive for efaAfm gene. Rest all the strains were negative for other tested virulence factors.

\section{Adherence assay}

The strains were screened for their ability to take up the congo red dye. Biofilm-forming bacteria are known to give pigmented colonies.
All the strains took up the dye giving pigmented colonies. The strains were further studied for their ability to adhere to the polystyrene plate for $2 \mathrm{~h}$. The adhesion was determined by turbidity caused by crystal violet stain bound to bacteria adhering to the polystyrene plate. The assay revealed the significant differences in the adherence properties of the strains. E. canintestini AB1, E. villorum SB2, E. rivorum $\mathrm{S} 22 \mathrm{C}$, and E. rivorum $\mathrm{S} 14 \mathrm{~B}$ show the highest adhesion values (Fig. 2). The remaining strains E. phoeniculicola S20A, E. canintestini S18A, E. canintestini S26B, and E. canintestini SB3 show lower adherence abilities. 
MATS

Fig. 3 shows the graph of strain adhesion to solvents. Chloroform proved to be the best solvent for adhesion. Significant strain-solvent interaction $(\mathrm{p}<0.05)$ was observed with increase in time. Strains E. dispar S27A, E. villorum SB2, E. canintestini S26B, E. rivorum S14B, and $E$. dispar S26A showed affinity values above $60 \%$ elucidating the monopolarity toward chloroform, while, strains showed lower affinity for ethyl acetate and xylene $(\leq 40 \%)$. These values were much higher than the reference strain used L. casei Shirota.

\section{Quantification of hydrogen peroxide}

Fig. 4 shows the $\mathrm{H}_{2} \mathrm{O}_{2}$ production profile of enterococcal strains. E. rivorum $\mathrm{S} 22 \mathrm{C}$ showed higher ability to produce $\mathrm{H}_{2} \mathrm{O}_{2}(1.054 \mathrm{mg} / \mathrm{ml})$.

\section{Autoaggregation and coaggregation assay}

The autoaggregation was checked by a decrease in the turbidity. The autoaggregation increased with increase in time.

The autoaggregation and coaggregation property varied in between the strains. The autoaggregation property was strain specific. Fig. 5 shows that several enterococcal strains displayed autoaggregation in between $20-50 \%$ after 4 h. E. canintestini AB1 (50.8 \pm 0.9$)$ was the highest, followed by $E$. canintestini S26B (50.6 \pm 0.88$),$ E. canintestini AB2 (48.43 \pm 1.16$)$, and E. canintestini SB3 (42.168 \pm 1.21$)$, while the other strains lay between $22-40 \%$. E. canintestini strains exhibited the highest aggregation values among all the strains though it was less than the reference strain used $L$. casei Shirota (77.45 \pm 1.1$)$. E. dispar S27A (74.137 \pm 1.2$)$, E. canintestini SB3 $(73.37 \pm 1.34)$, and E. canintestini S18A $(72.49 \pm 0.72)$ displayed excellent coaggregation properties against E. coli. Coaggregation was also observed with other indicator pathogens such as P. aeruginosa ATCC 27853, K. pneumoniae ATCC 13883, and $S$. typhi ATCC 6539. Fig. 6 shows the coaggregation property of all the strains. The autoaggregation and coaggregation ability significantly $(\mathrm{p}<0.05)$ increased with time.

\section{DISCUSSION}

The viability of probiotic strains in the presence of digestive enzymes is requisite for survival and healthy functioning of the GIT [4]. The study reveals the viability of Enterococcus strains in the presence of pancreatic enzymes. Similar results were reported in a study conducted on enterococcal isolates from commercial probiotic products. The Enterococcus strains could maintain $10^{6}-10^{9} \mathrm{cfu} / \mathrm{ml}$ of viability $[19,9]$. The study reveals the harshness of the $\alpha$-amylase enzyme by reducing the cell viability 2 times the original count. Amylase enzyme is known for disrupting the polysaccharide glucan linkages in the bacterial cell walls. The digestive enzymes degrade the food into macromolecules, and the acids aim to destroy foreign bodies such as bacteria and viruses thereby protecting the lining of the stomach. Hence, it is essential to select probiotic strains that sustain such harsh conditions. The effects of pancreatic enzymes can be reduced by encapsulating the bacteria in several protective substrates such as whey protein, alginate, and locust gums $[21,22,28]$.

Almost all of the strains exhibited broad-spectrum activity against enteric pathogens. The inhibitory zone can be exhibited by the secretion of organic acids, bacteriocins, or hydrogen peroxide production by the enterococci. Enterococcus strains isolated from the cecum of non-broiler chicken have been studied and are known to produce bacteriocins with antimicrobial activity $[29,30]$ The antagonistic activity is related in literature. The present investigation showed that the enterococci in the study had higher inhibitory activity than the results shown by E. durans Lab 18s strain [3]. Hence, there is a possibility that these enterococci and other useful lactic acid bacteria have an important role in pathogen exclusion.

Enterococci are commensals of GIT and urogenital systems of humans and animals. They inhabit environments contaminated by feces, sewage water, as well as fermented foods. Recently, the usage of enterococci in fermented foods and therapeutic use has raised its safety concerns. Some specific strains have known to be the cause of skin infections and diseases due to the disruption of the gut microbiota. Enterococci are opportunistic pathogens and are known to carry virulence factors. Hence, screening and eliminating virulent strains are the need of the hour. Hence, we first checked the safety profile of enterococcal strains by its susceptibility to the antibiotics. The antibiotics used in the study were clinically relevant and often used in the treatment of nosocomial infections. In the present study, none of the strains were resistant to these antibiotics. Vancomycinresistant enterococci are on the rise and the antibiotic is widely used for curing human infections. Many pathogenic strains have evolved harboring the antibiotic resistance genes. Enterococci are known to acquire resistance by carrying these genes located in plasmids and transposons. Some antibiotic-resistant enterococci have been isolated from Brazilian cheeses [4]. According to FAO and EFSA, the possession of virulent genes does not necessarily generalize the organism to be pathogenic, as the expression of these genes is extremely dependent on environmental conditions [18]. However, certain reports have also suggested the use of antibiotic-resistant probiotic bacteria to be beneficial for patients suffering from antibiotic-associated diarrhea [31].

We also checked the presence of virulence determinants by molecular methods. The strains in the present study revealed the absence of the

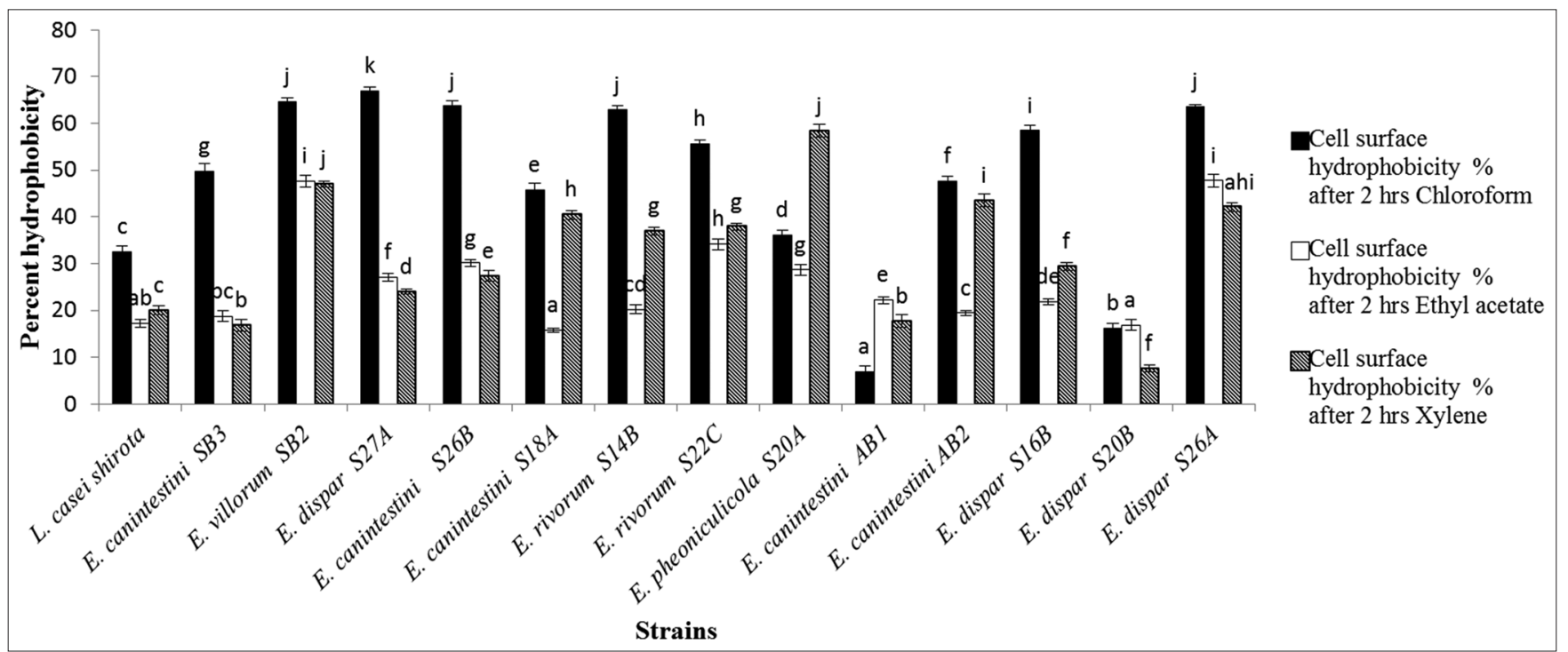

Fig. 3: Percent cell surface hydrophobicity of Enterococcus strains by MATS assay. 


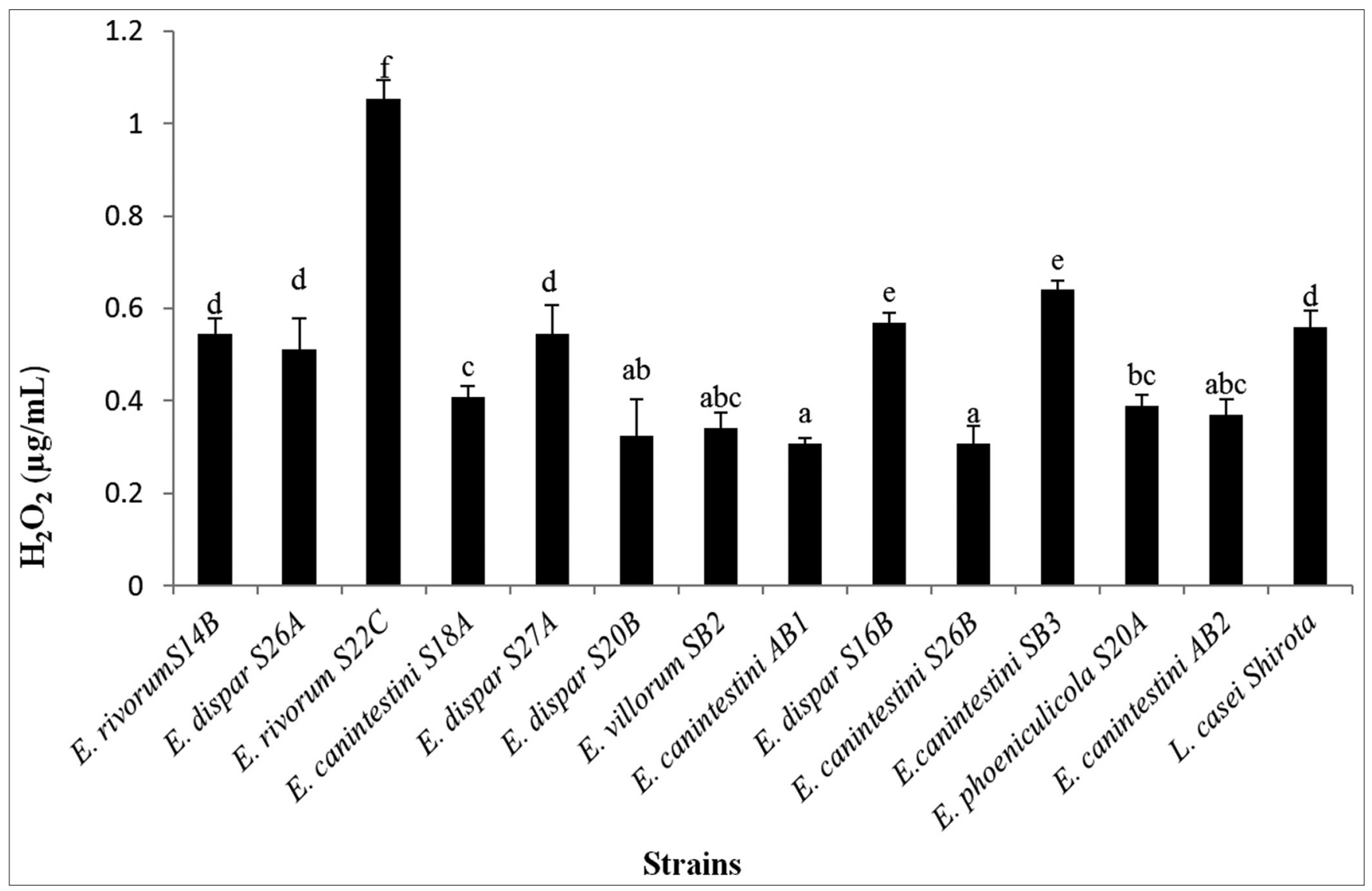

Fig. 4: Hydrogen peroxide production by Enterococcus strains

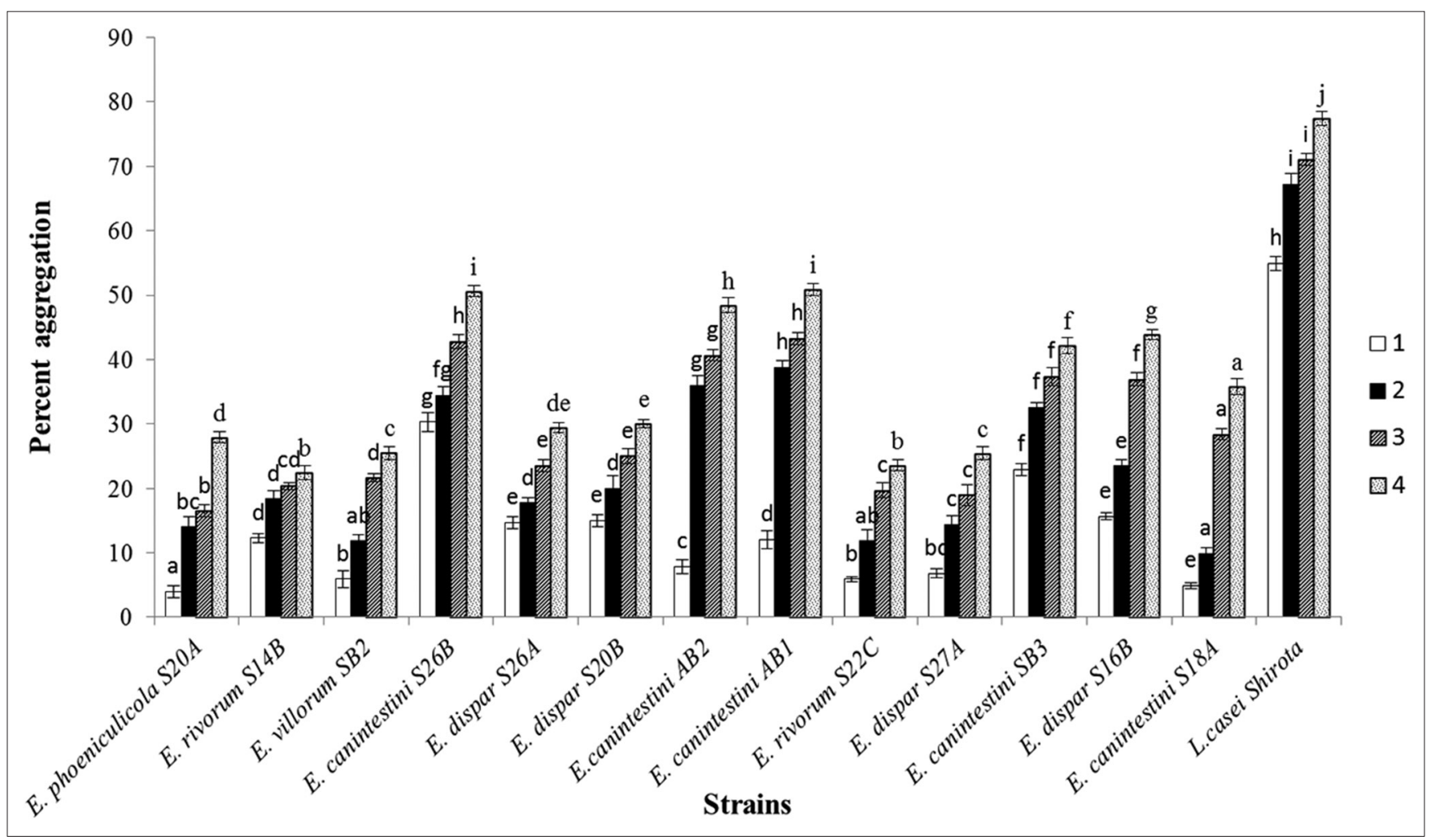

Fig. 5: Autoaggregation property of Enterococcus strains after $1 \mathrm{~h}, 2 \mathrm{~h}, 3 \mathrm{~h}$, and $4 \mathrm{~h}$

important virulence factors. These factors are possibly associated with the colonization and pathogenesis of enterococci. Gel $\mathrm{E}$ is a metalloprotease enzyme that hydrolyzes gelatine, casein, and other peptides. In our study, Gel E was absent in all tested strains. A previous 
study has reported that this factor is more prevalent in clinical isolates than in stool samples of healthy individuals. E. faecium and E. faecalis have been found to carry this gene frequently. Cytolysin is an erythrocyte-lysing protein and is thought to have an important part in human infections. It has been previously found in clinical strains $(11-70 \%)$ while $(0-25 \%)$ of stool samples. Three strains were positive for efaAfm and negative for all other virulence determinants (Table 5). These factors cannot be considered as important virulence factors as their prevalence rate is lower in human samples as compared to previous studies. This might be attributed to the differences in the host and distribution in geographical regions. Furthermore, Franz et al. have previously reported that the presence of one or more virulence determinants does not necessarily make a strain pathogenic.

Biofilm formation has been attributed to the production of inhibitory exopolysaccharides by the aggregation substance agg, enterococcal cell-surface protein esp genes, and collagen- binding proteins in several studies conducted in E. faecium and E. faecalis. This factor is condition dependent and necessary in the colonization of this strain into the GIT, in turn, contributing to the inhibition of pathogenic strains by competitive exclusion mechanism. The formation of biofilm also helps in greater inhibitory secondary metabolite production required in the elimination of pathogens. Recent studies have shown that antibioticresistant enterococcal strains such as E. faecalis isolated from hospital patients possess this gene in large numbers. However, the expression of these genes was found to be condition dependent and opportunistic. Thus, careful screening of non-resistant enterococcal strains for biofilm properties in probiotic foods may help in delivering its functions in the GIT $[25,26,27]$.

One of the best ways of checking the inhibitory properties of probiotic strains is by assessing antibiofilm activity against pathogens of GIT. This property of the strains contributes to the exclusion of pathogens from the GIT. The present study revealed that increasing concentrations of supernatant lead to a decrease in the growth of pathogens and thus inhibition of colonization. Similar results were reported for $L$. pentosus and $L$. plantarum against B. cereus and P. aeruginosa [21]. The probiotic strains eliminate pathogens by inhibiting their growth and progression toward biofilm formation by secreting various acids and bacteriocins. This ability helps in fighting the infectious agents in the intestine thus flourishing the healthy gut microbiome. Some studies have also reported that the biopolymers or EPS from enterococci have contributed to the inhibition of biofilm formation by the pathogens [33-35].

Adhesion is an essential step in the colonization of probiotic bacteria in the GIT. It is essential to know the time of adhesion of beneficial bacteria. Literature has reported that probiotic bacteria that are present in the gut for at least $2-3 \mathrm{~h}$ show good adhesion properties. The intestinal microbiota washes out the pathogenic invading bacteria from the GIT. This function prevents the probiotic cells from adhesion [36].

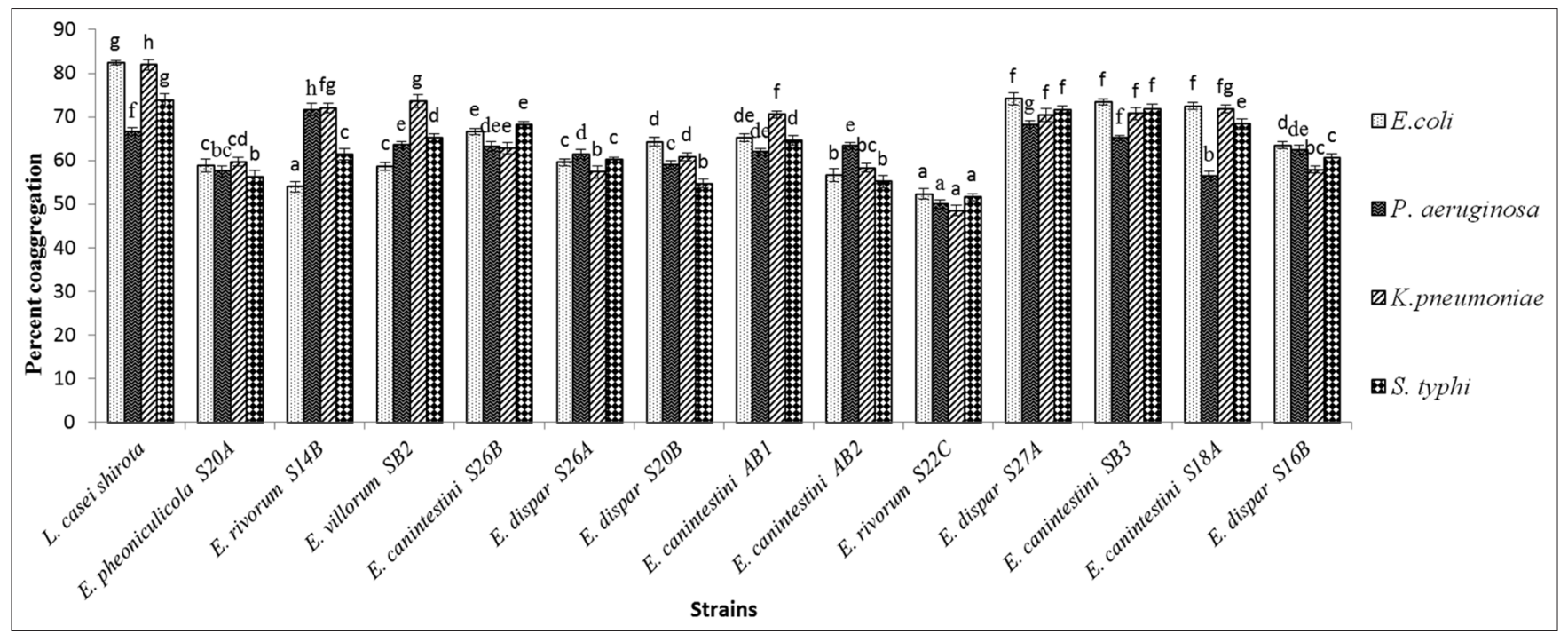

Fig. 6: Coaggregation property of Enterococcus strains with pathogens

Table 5: Screening of virulence factors

\begin{tabular}{|c|c|c|c|c|c|c|}
\hline Strains & cyl A & $\operatorname{van} A$ & $\operatorname{van} B$ & gel E & efaAfs & efaAfm \\
\hline E. villorum SB2 & - & - & - & - & - & - \\
\hline E. phoeniculicola S20A & - & - & - & - & - & + \\
\hline E. rivorum $\mathrm{S} 14 \mathrm{~B}$ & - & - & - & - & - & - \\
\hline E. canintestini $\mathrm{AB} 2$ & - & - & - & - & - & - \\
\hline E. rivorum $\mathrm{S} 22 \mathrm{C}$ & - & - & - & - & - & - \\
\hline E. canintestini S18A & - & - & - & - & - & + \\
\hline E. canintestini SB3 & - & - & - & - & - & - \\
\hline E. canintestini $\mathrm{AB} 1$ & - & - & - & - & - & - \\
\hline E. dispar $\mathrm{S} 16 \mathrm{~B}$ & - & - & - & - & - & - \\
\hline E. dispar $\mathrm{S} 26 \mathrm{~A}$ & - & - & - & - & - & - \\
\hline E. dispar S 27A & - & - & - & - & - & + \\
\hline E. canintestini S26B & - & - & - & - & - & - \\
\hline E. dispar $\mathrm{S} 20 \mathrm{~B}$ & - & - & - & - & - & - \\
\hline L. casei Shirota & - & - & - & - & - & - \\
\hline
\end{tabular}

E. phoeniculicola S20A, E. canintestini S18A, and E. dispar S 27A were positive for efaAfm gene. Rest all the strains were negative for other tested virulence factors. E. villorum: Enterococcus villorum, E. phoeniculicola: Enterococcus phoeniculicola, E. rivorum: Enterococcus rivorum, E. canintestini: Enterococcus canintestini,

E. dispar: Entamoeba dispar, L. casei Shirota: Lactobacillus casei Shirota 
The cells should not be washed off by the gastric mucosal secretions. Hence, we studied the total adhesion of bacteria in $2 \mathrm{~h}$ of incubation. The adhesion property of microbial cells can be evaluated by adhesion to certain substances such as polystyrene, mucus, glass, and plastic. This factor is necessary for host-microbe interactions and pathogen exclusion. It is also necessary that probiotic bacteria should persist in the gut for a longer period of time and provide long-term benefits by eliminating pathogens and creating healthy gut microbiota [22]. The adherence is mediated by cell-signaling pathways with the involvement of various cell- signaling proteins and also lipoteichoic acids of the bacteria. Several bacterial cell surface proteins play an important role in adhesion to mucosal surfaces. They are also considered as virulence factors in progressing infection. The adhesion property of bacteria as previously described helps in colonizing and competitive exclusion of pathogens. Hence, probiotic bacteria used in functional food, must surpass the harsh environment of the GIT and successfully colonize themselves in the gut [37].

Bacterial adhesion can be initiated by hydrophobicity and Lewis-acidbase characteristics. Hence, it is important to study the bacterial cell surface interactions between polar and apolar solvents. Chloroform was used as an acidic solvent and electron acceptor; ethyl acetate as basic solvent with electron donating properties; xylene was used as an apolar solvent in the evaluation of hydrophobicity and hydrophilicity studies [24].

Chloroform, ethyl acetate, and xylene revealed different hydrophobicity degrees with different strains. Similar results were observed while working with $L$. acidophilus M92 and $L$. plantarum strains [14,17]. However, the bacterial adhesion to solvents is not a prerequisite factor for cell adhesion. The cell surface hydrophobicity is weak non-specific interactions at first and irreversible. It is then progressed to adhesion by mediating specific signals between the cell surface proteins and lipoteichoic acids. A similar range of hydrophobicity values were reported for E. faecium isolated from Bulgarian feta cheese [38]. The isolated strains displayed much higher hydrophobicity values than E. faecium EM 485 (8.18\%) and E. faecium EM 925 (11.33 \%) [4]. The stronger the cell surface hydrophobicity, greater will be the adhesion to the mucosal cells. This, in turn, helps in the survival and attachment of the probiotic bacteria in the intestinal tract for longer periods of time. The hydrophobicity factor is not particularly compulsory for cell adhesion but is thought to assist in cell adhesion. This property is seen to vary among various strains among the species [39].

Hydrogen peroxide is an important secondary metabolite produced by all lactic acid bacteria. The present study reveals the hydrogen peroxide producing a potential of the enterococci. Agboola F. M. observed similar results while studying vaginal lactobacillus isolates $L$. lactis and $L$. acidophilus $(0.0042 \mathrm{~g} / \mathrm{ml})$ [40]. It plays an important role in antagonistic activity against pathogens by exerting a strong oxidizing effect on the cell and destructs the cellular proteins. This property of hydrogen peroxide contributes to pathogen exclusion of urogenital infections. In the presence of copper and iron, hydrogen peroxide is known to produce highly reactive $\mathrm{OH}$ - free radicals. These radicals attack the polyunsaturated fatty acids on bacterial cell membranes initiating lipid peroxidation. This, in turn, alters the fluidity in membranes leading to cell death of pathogens [41].

The autoaggregation and coaggregation abilities of bacteria are also mediated by cell-signaling pathways. Aggregation and coaggregation were seen in most of the tested enterococci strains in the present study. In a similar study conducted from Bulgarian feta cheese, much lower aggregation properties were seen in E. faecium and E. faecalis [42]. Furthermore, similar values were reported by L. paracasei ST284BZ and L. pentosus ST712BZ [43]. Similar results were reported by Dos Santos et al., in her study on E. faecium isolated from Brazilian cheese and $E$. coli (78 \pm 2$)$ [4]. Favaro et al. too found a varying degree of percentage of this property in his study [42]. Strains with self-aggregation ability below $10 \%$ are considered as non-aggregating [44]. Greater cell surface hydrophobicity can be caused due to the presence of glycoproteins on the cell-surface which result in specific binding self-aggregation of organisms [45]. Self-aggregation may contribute to biofilm formation thus eliminating pathogens by competitive exclusion mechanism. The higher coaggregation ability helps in the excretion of inhibitory substances by the probiotic bacteria thus eliminating the pathogens from the GIT. Furthermore, lower values of the coaggregation may prevent biofilm formation by the pathogens $[20,24]$.

\section{CONCLUSIONS}

The present study has reported the possible probiotic potential of Enterococcus strians of human origin. They proved to be anti-pathogenic, adherent, antibiotic sensitive, and tolerant to pancreatic enzymes. Although these bacteria have proved some of their in vitro probiotic properties, it is essential to check their properties in vivo to prove them safe for probiotic purpose. These isolates can be considered as probiotic candidates for human or animal consumption only after required clinical studies.

\section{ACKNOWLEDGMENT}

We would like to thank University of Grants Commissin- Basic Science Reasearch (UGC-BSR) for funding this project. We also thank Dr. Y. S. Nandanwar of Lokmanya Tilak General Municipal Hospital for providing us the necessary samples.

\section{CONFLICTS OF INTEREST}

The authors declare that they have no conflicts of interest.

\section{AUTHORS' CONTRIBUTIONS}

Miss. Ashlesha N. Bhagwat- Main author (first author) initiated conducted the research and prepared the manuscript

Dr Y. S. Nandanwar, Dr. Rahul Warke - Concept and ideology of research

Prof. Uday S. Annapure - Corresponding author, supervision of research, and edited the manuscript

\section{REFERENCES}

1. FAO and WHO. Health and Nutritional Properties of Probiotics in Food Including Powder Milk with Live Lactic Acid Bacteria. Córdoba: FAO WHO; 2001. p. 1-34

2. Simpson KW, Rishniw M, Bellosa M, Liotta J, Lucio A, Baumgart M, et al. Influence of Enterococcus faecium SF68 probiotic on giardiasis in dogs. J Vet Intern Med 2009;23:476-81

3. Pieniz S, Andreazza R, Anghinoni T, Camargo F, Brandelli A. Probiotic potential, antimicrobial and antioxidant activities of Enterococcus durans strain LAB18s. Food Control 2014;37:251-6.

4. Dos Santos KM, Vieira AD, Salles HO, Oliveira Jda S, Rocha CR, Borges Mde F, et al. Safety, beneficial and technological properties of Enterococcus faecium isolated from brazilian cheeses. Braz J Microbiol 2015;46:237-49.

5. Ming Lei, Xianjun Dai ML. Biological Characteristics and Safety Examination of Five Enterococcal strains from Probiotic Products : Five Enterococcal strains of five Enterococcal strains from probiotic products. J Food Safety 2016;35:324-335.

6. Wunderlich PF, Braun L, Fumagalli I, D’Apuzzo V, Heim F, Karly M, et al. Double-blind report on the efficacy of lactic acid-producing enterococcus SF68 in the prevention of antibiotic-associated diarrhoea and in the treatment of acute diarrhoea. J Int Med Res 1989;17:333-8.

7. Luong ML, Sareyyupoglu B, Nguyen MH, Silveira FP, Shields RK, Potoski BA, et al. Lactobacillus probiotic use in cardiothoracic transplant recipients: A link to invasive lactobacillus infection? Transpl Infect Dis 2010;12:561-4.

8. Bhardwaj S, Bhamre K, Dhawale J, Patil M, Divase S. Enterococus faecium and Enterococus faecalis, the nosocomial pathogens with special reference to multi-drug resistance and phenotypic characterization. Int J Pharm Sci Pract 2013;2:1-10.

9. EFSA. Guidance on the assessment of bacterial susceptibility to antimicrobials of human and veterinary importance prepared by the 
EFSA panel on additives and products of substances used in animal feed (FEEdAP). EFSA J 2012;10:2740.

10. Pettker CM, Buhimschi IA, Magloire LK, Sfakianaki AK, Hamar BD, Buhimschi CS, et al. Value of placental microbial evaluation in diagnosing intra-amniotic infection. Obstet Gynecol 2007;109:739-49.

11. Jiménez E, Fernández L, Marín ML, Martín R, Odriozola JM, NuenoPalop C, et al. Isolation of commensal bacteria from umbilical cord blood of healthy neonates born by cesarean section. Curr Microbiol 2005;51:270-4.

12. Satokari R, Grönroos T, Laitinen K, Salminen S, Isolauri E. Bifidobacterium and Lactobacillus DNA in the human placenta. Lett Appl Microbiol 2009;48:8-12.

13. Pandey PK, Verma P, Kumar H, Bavdekar A, Patole MS, Shouche YS, et al. Comparative analysis of fecal microflora of healthy full-term Indian infants born with different methods of delivery (vaginal vs cesarean): Acinetobacter sp. Prevalence in vaginally born infants. J Biosci 2012;37:989-98.

14. Collins JK, Thornton G, Sullivan GO. Selection of probiotic strains for human applications. Int Dairy J 1998;8:487-90.

15. Bhardwaj A, Gupta H, Kapila S, Kaur G, Vij S, Malik RK. Safety assessment and evaluation of probiotic potential of bacteriocinogenic Enterococcus faecium $\mathrm{KH} 24$ strain under in vitro and in vivo conditions. Int J Food Microbiol 2010;141:156-64.

16. Shukla G, Sharma G, Goyal N. Probiotic characterization of Lactobacilli and yeast strains isolated from whey beverage and therapeutic potential of Lactobacillus Yoghurt Murine Giardiasis 2010;2:248-61

17. Sreeja S, Babu P R S, Prathab AG. The prevalence and the characterization of the Enterococcus species from various clinical samples in a tertiary care hospital. J Clin Diagn Res 2012;6:1486-8.

18. EFSA FEEDAP Panel. Scientific Opinion on the safety and efficacy of Enterococcus faecium (NCIMB 10415, DSM 22502, ATCC 53519 and ATCC 55593) as silage additives for all animal species 1. EFSA J 2013;11:1-22

19. Eaton TJ, Gasson MJ. Molecular screening of Enterococcus virulence determinants and potential for genetic exchange between food and medical isolates. Appl Environ Microbiol 2001;67:1628-35.

20. Lebeer S, Verhoeven TL, Perea Vélez M, Vanderleyden J, De Keersmaecker SC. Impact of environmental and genetic factors on biofilm formation by the probiotic strain Lactobacillus rhamnosus GG. Appl Environ Microbiol 2007;73:6768-75.

21. Khiralla GM, Mohamed EA, Farag AG, Elhariry H. Antibiofilm effect of Lactobacillus pentosus and Lactobacillus plantarum cell-free supernatants against some bacterial pathogens. J Bio Res 2015;6:86-95.

22. Mahdhi A, Hmila Z, Behi A, Bakhrouf A. Preliminary characterization of the probiotic properties of candida famata and geobacillus thermoleovorans. Iran J Microbiol 2011;3:129-34.

23. Heikens E, Bonten MJ, Willems RJ. Enterococcal surface protein esp is important for biofilm formation of Enterococcus faecium E1162. J Bacteriol 2007; 189:8233-40.

24. Valeriano VD, Parungao-Balolong MM, Kang DK. In vitro evaluation of the mucin-adhesion ability and probiotic potential of Lactobacillus mucosae LM1. J Appl Microbiol 2014;117:485-97.

25. Saranya S, Hemashenpagam N. Purification and characterization of bacteriocin produced by different Lactobacillus species isolated from fermented foods. Int J MicroBiol Res 2013;5:341-8.

26. Dias FS, Duarte WF, Schwan RF. Evaluation of adhesive properties of presumptive probiotic Lactobacillus plantarum strains. Biosci J 2013;29:1678-86.

27. Doherty SB, Auty MA, Stanton C, Ross RP, Fitzgerald GF, Brodkorb A. Survival of entrapped Lactobacillus rhamnosus GG in whey protein micro-beads during simulated ex vivo gastro-intestinal transit. Int Dairy J 2012;22:31-43.
28. Gbassi GK, Vandamme T. Probiotic encapsulation technology: From microencapsulation to release into the gut. Pharmaceutics 2012;4:149-63.

29. Yusuf MA, Ichwan SJ, Hamid TH. Anti-proliferative activities of purified bacteriocin from Enterococcus mundtii strain c4110 isolated from the caecum of malaysian non-broiler chicken on cancer cell lines. Int J Pharm Pharm Sci 2015;7:334-7.

30. Yusuf MA, Haziyamin T, Hamid A. Detection and characterization of enterocin encoding genes in Enterococcus mundtii strain c4110 from the cecum of non-broiler chicken. Int J Pharm Pharm Sci 2015;7:131-6.

31. Szajewska H, Canani RB, Guarino A, Hojsak I, Indrio F, Kolacek S, et al. Probiotics for the prevention of antibiotic-associated diarrhea in children. J Pediatr Gastroenterol Nutr 2016;62:495-506.

32. Franz CMAP, Muscholl-Silberhorn AB, Yousif NMK, Vancanneyt M, Swings J, Holzapfel WH. Incidence of virulence factors and antibiotic resistance among enterococci isolated from food. Appl Environ Microbiol 2001. doi:10.1128/AEM.67.9.4385-4389.2001.

33. Tendolkar PM, Baghdayan AS, Shankar N. Putative surface proteins encoded within a novel transferable locus confer a high-biofilm phenotype to Enterococcus faecalis. J Bacteriol 2006;188:2063-72.

34. Alexandre Y, Le Berre R, Barbier G, Le Blay G. Screening of Lactobacillus spp. For the prevention of Pseudomonas aeruginosa pulmonary infections. BMC Microbiol 2014;14:107.

35. Kanmani P, Satish kumar R, Yuvaraj N, Paari KA, Pattukumar V, Arul V, et al. Production and purification of a novel exopolysaccharide from lactic acid bacterium Streptococcus phocae PI80 and its functional characteristics activity in vitro. Bioresour Technol 2011;102:4827-33.

36. Adlerberth I, Cerquetti M, Poilane I, Wold A, Collignon A. Mechanisms of colonisation and colonisation resistance of the digestive tract: Part 1: Bacteria/host interactions. Microb Ecol Health Dis 2000;12:223-39.

37. Balakrishna A. In vitro evaluation of adhesion and aggregation abilities of four potential probiotic strains isolated from guppy (Poecilia reticulata). Braz Arch Biol Technol 2013;56:793-800.

38. Ramos CL, Thorsen L, Schwan RF, Jespersen L. Strain-specific probiotics properties of Lactobacillus fermentum, Lactobacillus plantarum and Lactobacillus brevis isolates from Brazilian food products. Food Microbiol 2013;36:22-9.

39. Schär-Zammaretti P, Ubbink J. The cell wall of lactic acid bacteria: Surface constituents and macromolecular conformations. Biophys $\mathrm{J}$ 2003;85:4076-92.

40. Agboola FM. Probiotic potentials of lactic acid bacteria isolated from vaginal swabs on selected genital pathogens. Int J Pharm Sci Res 2014;5:2642-50

41. Kheadr E, Dabour N, Le Lay C, Lacroix C, Fliss I. Antibiotic susceptibility profile of bifidobacteria as affected by oxgall, acid, and hydrogen peroxide stress. Antimicrob Agents Chemother 2007;51:169-74.

42. Favaro L, Basaglia M, Casella S, Hue I, Dousset X, Gombossy de Melo Franco BD, et al. Bacteriocinogenic potential and safety evaluation of non-starter Enterococcus faecium strains isolated from home made white brine cheese. Food Microbiol 2014;38:228-39.

43. Furtado DN, Todorov SD, Landgraf M, Destro MT, Franco BD. Bacteriocinogenic Lactococcus lactis subsp. Lactis DF04Mi isolated from goat milk: Evaluation of the probiotic potential. Braz J Microbiol 2014;45:1047-54.

44. Del Re B, Sgorbati B, Miglioli M, Palenzona D. Adhesion, autoaggregation and hydrophobicity of 13 strains of Bifidobacterium longum. Lett Appl Microbiol 2000;31:438-42.

45. Kos B, Susković J, Vuković S, Simpraga M, Frece J, Matosić S, et al. Adhesion and aggregation ability of probiotic strain Lactobacillus acidophilus M92. J Appl Microbiol 2003;94:981-7. 